\title{
Definitions and Epidemiology of Endodontic Infections
}

\author{
I. F. Persoon ${ }^{1}$ A. R. Özok ${ }^{2}$
}

Published online: 8 November 2017

(C) The Author(s) 2017. This article is an open access publication

\begin{abstract}
Purpose of Review This review describes the recent findings from epidemiological studies on endodontic infections. The recent literature was screened for studies on the prevalence of primary apical periodontitis and posttreatment apical periodontitis in various populations.

Recent Findings Twenty-nine articles reporting data on the prevalence of primary or posttreatment apical periodontitis from all over the world were included. The prevalence of apical periodontitis varied between 7 and $86 \%$, while that of posttreatment apical periodontitis varied between 10 and $62 \%$. The quality of the coronal restoration and the root filling appears to be the major predictors of apical periodontitis.

Summary The recent findings from epidemiological studies on the prevalence of primary and posttreatment apical periodontitis in various populations are not substantially different from those from earlier years. It appears that the health of periapical tissues has not majorly improved in the general population.
\end{abstract}

Keywords Endodontic infections $\cdot$ Epidemiology $\cdot$ Primary apical periodontitis $\cdot$ Posttreatment apical periodontitis .

Prevalence

This article is part of the Topical Collection on Epidemiology

A. R. Özok

r.ozok@acta.nl

1 Department of Preventive Dentistry, Academic Centre for Dentistry Amsterdam (ACTA), University of Amsterdam and Vrije Universiteit Amsterdam, Amsterdam, The Netherlands

2 Department of Endodontology, Academic Centre for Dentistry Amsterdam (ACTA), University of Amsterdam and Vrije Universiteit Amsterdam, Gustav Mahlerlaan 3004, 1081 LA Amsterdam, The Netherlands

\section{Introduction}

\section{Definition of Endodontic Infections}

The root canal system is, in its healthy and intact state, free from infection. Unlike the oral cavity, the root canal system has no commensal microbiota, and any microorganism detected here can be regarded as a potential pathogen. Once microorganisms find their way into the root canal system, the consequences may vary from a simple reversible pulpitis to the necrosis of the pulpal tissue and eventually formation of a periapical lesion: apical periodontitis. Pulpal necrosis on its own, when no microorganisms are involved, does not necessarily lead to apical periodontitis [1]. Nevertheless, a necrotic pulp, following for example a mechanical or thermal trauma, can hardly maintain its 'sterile' status due to the lack of blood circulation and defense mechanisms that could eliminate intruding microorganisms. An infected root canal system is a prerequisite for the formation of apical periodontitis [2]. Apical periodontitis is an inflammatory response of the periapical periodontal tissues to the infected root canal system. A bony lesion is formed as calcified periapical tissues erode, caused by the toxic irritation deriving from the infected root canal and the immune response of the host.

The microorganisms identified within endodontic infections are a selection from the commensal microbiota of the oral cavity. The ecological conditions select for a certain microbiota. In a healthy oral ecosystem, microbiota live in homeostasis with the host. When the conditions change, for example by a diet rich in carbohydrates, certain microorganisms can dominate and cause disease. Dental decay may create access to a new niche: the root canal system. Since the ecological conditions are different from the oral cavity, microorganisms will be selected and establish a new microbial community. Although advancing analytical techniques have 
uncovered an immense diversity and variance of the microbiota within infections, a pattern according to the disease activity can be drawn: symptomatic versus asymptomatic [3]. The microorganisms that contribute the most to endodontic infections are bacteria, both in biomass and diversity [4]. Although Lactobacillus, Actinomyces, and Streptococcus are among the most abundant genera detected in root canals associated with apical periodontitis [5], regarding the aseptic nature of the root canal system in its healthy and intact state, any bacteria present can be regarded as an endodontic pathogen. Still, fungi [4], viruses [6], and archaea [7] can be detected within root canal infections and periapical lesions. Despite their low numbers, they might contribute significantly to the composition and virulence of the overall microbiota and to the host response. Such influence could lead to persistence and symptomology of the apical periodontitis.

\section{Possible Effect on Epidemiological Studies of the Diagnosis of Apical Periodontitis and the Definition of Its Severity}

Symptomatic apical periodontitis is characterized by the inflammation of the periapical tissues, generating clinical symptoms including a painful response to biting or percussion or tenderness with palpation. Depending on the phase of the disease, radiographic changes may or may not be detectable [1]. Asymptomatic apical periodontitis can, however, be solely diagnosed by the presence of radiographic changes, namely a periapical radiolucency created by the bony lesion on the radiograph.

The most commonly used radiographic detection methods for a periapical lesion are conventional or digital periapical radiography, panoramic radiography or, most recently, conebeam computed tomography (CBCT). Various degrees of diagnostic accuracy for each one of the abovementioned methods have been reported. In the premolar and mandibular molar regions, significantly more periapical lesions can be detected on conventional periapical radiographs than on panoramic radiographs [8].

Due to its three-dimensional nature, the $\mathrm{CBCT}$ stands out from the rest $[9,10]$. The diagnostic accuracy of CBCT in detecting apical periodontitis is significantly higher compared to digital periapical radiography [10] or panoramic radiography [11]. The possibility of false-negative diagnosis is, therefore, much higher when conventional two-dimensional radiography is used. This may pose a challenge for the diagnosis of the disease, which subsequently may have an impact on the findings of the studies on its prevalence leading to an underestimation. CBCT, on the other hand, has its own limitations with regard to epidemiological studies. Concerning the relatively high effective dose for $\mathrm{CBCT}$ and the as low as reasonably achievable (ALARA) principle, when a CBCT scan is made to diagnose apical periodontitis, it is recommended to use limited volume CBCT, in which the field of view (FOV) is limited to a volume smaller than the jaws and suitable for imaging only a few teeth [12]. This may negatively impact studies on the prevalence of apical periodontitis. When a small FOV is used, only a limited part of the dentition is evaluated, and the information about the prevalence of the disease in the rest of the dentition remains censored. From an epidemiological point of view, data collection only on the tooth level, instead of on a subject level, seems less relevant.

Not only the detection of periapical disease is challenging but also the definition of its severity. There seems to be little consensus on the degree of bone destruction at which a bony lesion can be defined as apical periodontitis. Several indexing methods have been introduced for the assessment of the severity of apical periodontitis, each with its limitations. The most commonly used method is the periapical index (PAI) [13], and it is reported to have excellent observer agreement [14]. The PAI scoring system aims to assess the severity of apical periodontitis on dental radiographs with the use of a 5score scale, where score 1 represents healthy periodontium and scores 2 to 5 , respectively, represent periapical disease increasing in severity [13]. This scoring system, however, is not based on direct histopathological examination, but on a simplified modification of the radiographic method of interpretation based on the histopathological examination executed by Brynolf [15]. Since Brynolf used only upper incisors in her study [15], the reliability of the PAI system in premolar or molar regions is unclear.

Another limitation of the PAI system and any other scoring system based on conventional or digital radiographs is related to the two-dimensional nature of these radiographs. While it is, to a certain extent, possible to measure the diameter of the lesion in the mesial-distal direction on a two-dimensional radiograph, its diameter in the buccal-lingual direction remains unmeasurable. The surrounding anatomical structures and the thickness of the bone can further obscure the lesion on the radiograph. This is an even greater problem for multirooted teeth.

There is no clear consensus on the description of apical periodontitis in epidemiological studies using the PAI system screened in this review. While some studies accepted only a PAI score of 1 as healthy apical periodontium [16, 17], many others included a PAI score of 2 in the healthy category as well $[18-30,31 \bullet]$ or even a PAI score of 3 [32].

\section{The Incidence and Prevalence of Apical Periodontitis}

Unfortunately, studies into new diagnoses of endodontic infections per time period, the incidence, are not feasible, since the detection of the onset of the periapical disease is nearly impossible. The time needed for apical periodontitis to become visible on the radiograph is relatively long and depends on several factors. A substantial amount of trabecular bone 
mineral loss or the erosion of the cortical bone is needed for the lesion to become radiographically visible [33]. Therefore, most studies on the epidemiology of endodontic infections focus on their prevalence, where the proportion of a population with apical periodontitis is estimated based on examination of a sample of the population of interest.

\section{Recent Findings on the Prevalence of Apical Periodontitis}

This review identified relevant studies using a search of the MEDLINE electronic database via PubMed and from the reference list of relevant articles. The search strategy, limited to a period from January 2014 to May 2017, identified the terms 'apical periodontitis' and 'epidemiology' or 'prevalence' and generated 103 hits. Only 51 of these titles were actually related to the search terms. After screening these abstracts, 45 relevant articles were selected for full-text reading. Twenty-nine articles reporting cross-sectional data of epidemiological studies met the inclusion criteria (Table 1). Studies using tooth as the unit of estimation were included only if the data were applicable to subject level or the general population. Outcome studies were excluded, since these only assess the targeted root-filled teeth. Review articles where the abovementioned criteria were not met or if it was not possible to extract this information were excluded as well. The current review defines teeth associated with apical periodontitis and without a root filling as teeth with primary apical periodontitis, and root-filled teeth associated with apical periodontitis as teeth with posttreatment apical periodontitis. Since not every study reported data on the prevalence of primary or posttreatment apical periodontitis separately, in the following part of the text, the term 'apical periodontitis' refers to a total of primary and posttreatment apical periodontitis.

Based on the included articles, the lowest prevalence of apical periodontitis on a patient level, meaning one or more periapical lesions per patient, was $7 \%$ in an otherwise healthy Spanish population [43], and the highest was $86 \%$ in a Croatian population of smokers [25] with a median of $52.5 \%$. The corresponding percentages for the prevalence of primary apical periodontitis, respectively, were $10 \%$ in a Finnish population [46] and 53\% in a Spanish population [23] with a median of $20.5 \%$. The lowest prevalence of rootfilled teeth on a patient level was $20 \%$ in an Australian population [31•], and the highest was $82 \%$ in a Croatian population of smokers [25] with a median of $61 \%$. The lowest prevalence of posttreatment apical periodontitis on a patient level was $10 \%$ in a Spanish population [23] and $62 \%$ in a Croatian population [25] with a median of $39 \%$.

The prevalence rates on tooth level were lower for each condition. The prevalence of apical periodontitis ranged from $2 \%$ in a Finnish population [32] to $14 \%$ in a Nigerian population [18]. The median was $6 \%$ on a total of 304,721 teeth, which compares well to the $5 \%$ found in a previous systematic review and meta-analysis [49••]. This review was on studies from 1987 till 2009 on a total of 300,861 teeth. The prevalence of primary apical periodontitis ranged from $1 \%$ in Finnish [32], French [41•], Swedish [34], and Australian [31•] populations to $13 \%$ in a Jordanian population of diabetics [26]. The median was $3.5 \%$, which is similar to the $2 \%$ from the previously mentioned meta-analysis [49••]. The slightly lower rate might be caused by a more systematic inclusion and also inclusion of studies from mainly well-developed countries. The prevalence of root-filled teeth ranged from $2 \%$ in an Australian population [31•] to $18 \%$ in a French population [41•]. The median was $6 \%$, which is in the same range as the $10 \%$ from the previously mentioned meta-analysis [49.0]. The lower prevalence of root-filled teeth in the more recently published studies (published from 2014) might indicate a limited access to oral healthcare, which is likely when studies are done in less-developed countries [30]. The prevalence of posttreatment apical periodontitis ranged from $20 \%$ in an otherwise healthy Jordanian population [26] to $65 \%$ in a Brazilian population [22]. The median was $41 \%$, which is similar to the $36 \%$ found in the previously mentioned metaanalysis [49••]. Overall, the prevalence rates seem similar to rates in not so recent studies (published prior to 2014), even though more recent studies (published from 2014) are done on samples from less-developed countries or individuals with access to newer treatment techniques.

\section{Gender}

The effect of gender on apical periodontitis remains ambiguous. Studies on Swedish [20], Nigerian [19], Danish [44], or Belgian [48] populations reported no significant difference in the prevalence of apical periodontitis between men and women. However, a significantly higher prevalence of apical periodontitis in men than in women was revealed in Turkish [38], Finnish [46], or Austrian [28] populations, while in Scottish [36], Jordanian [47], or Saudi Arabian [45] populations, the prevalence of apical periodontitis was higher in women than in men. It is quite challenging to explain the difference between the outcome of these studies. Research suggests that women perceive more pain [50] and are more likely to seek treatment for orofacial pain [51], possibly at an earlier, more treatable stage of the disease. Also, cultural characteristics of a population may affect the frequency a man or a woman seeks dental care. Since the results are ambiguous, the effect of gender on apical periodontitis remains unresolved.

\section{Quality of the Root Filling or the Coronal Restoration}

Both the quality of the coronal restoration and the quality (length or the density) of the root filling are reported to be major predictors of posttreatment apical periodontitis. There is a negative correlation between the quality of the coronal 


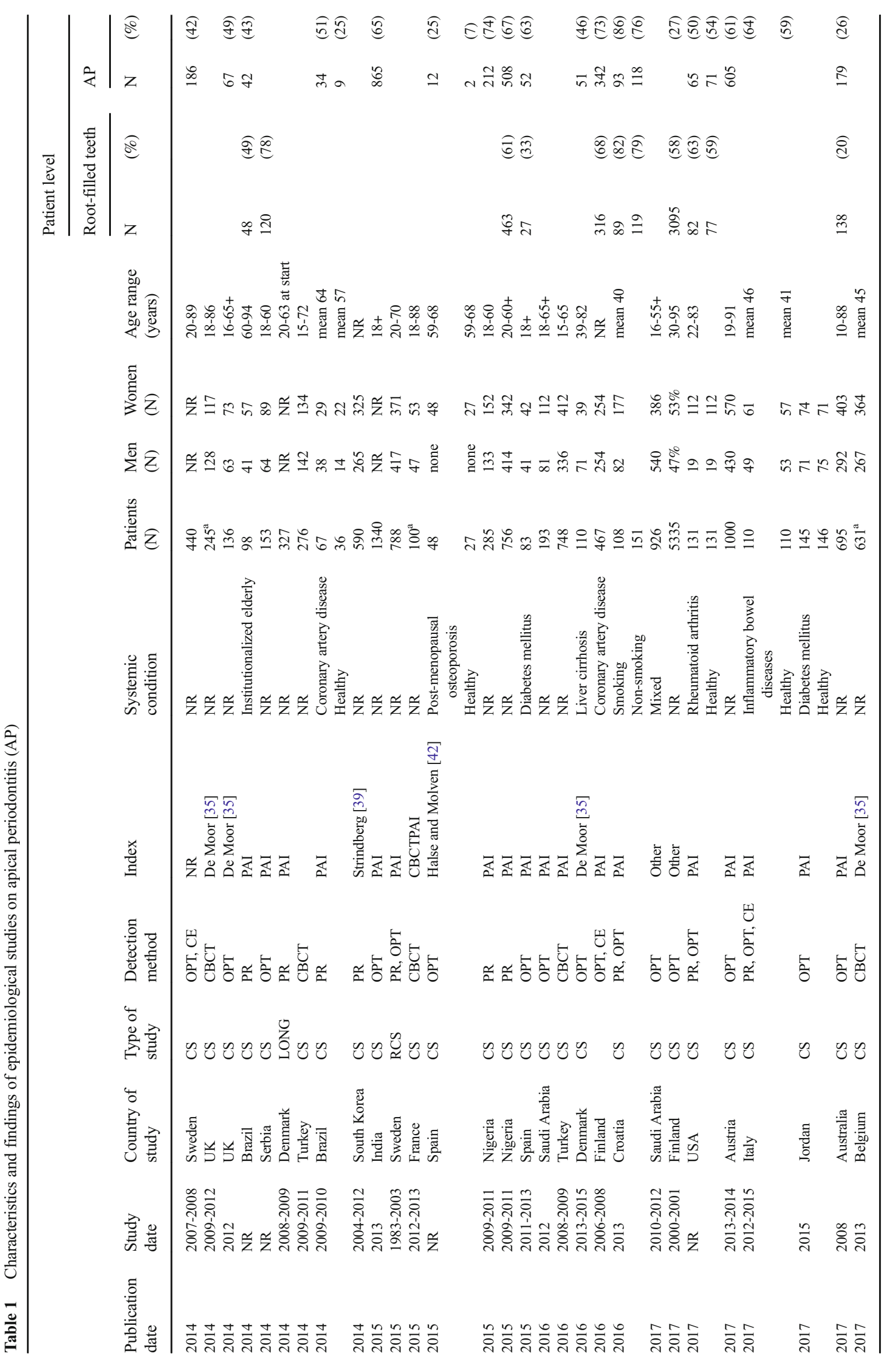




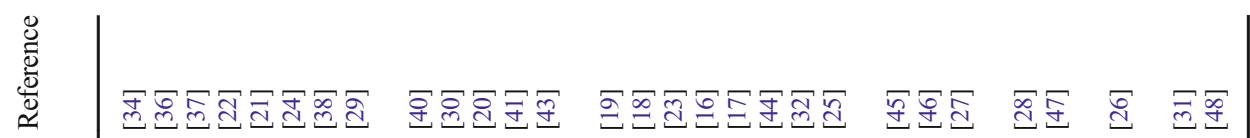

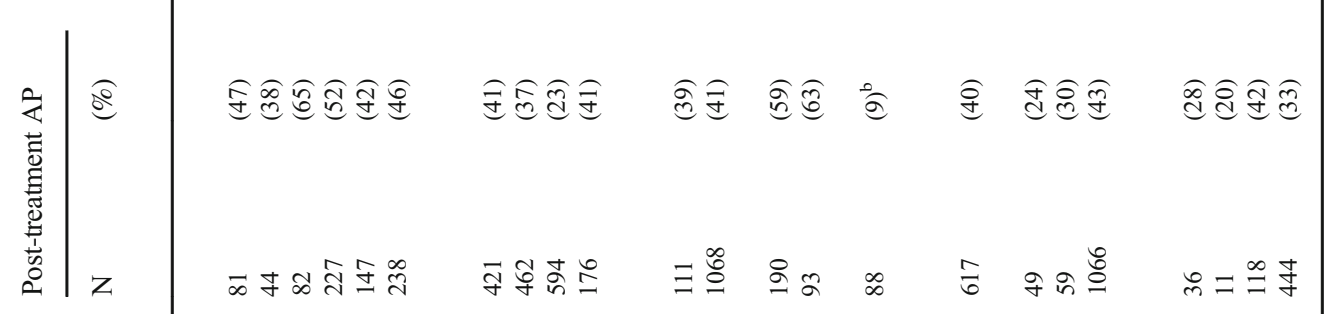

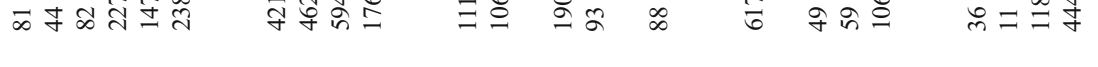

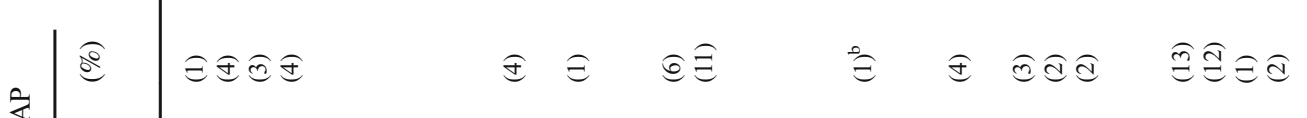

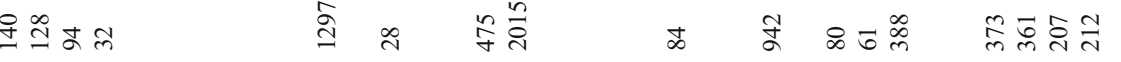

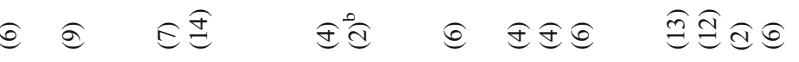

อำ $\widehat{\underline{\theta}}$

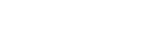

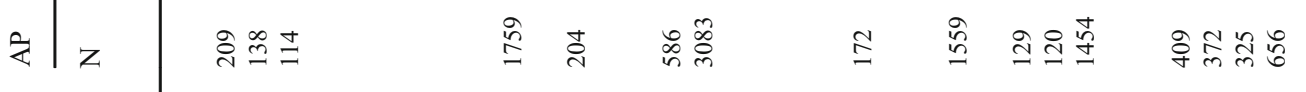

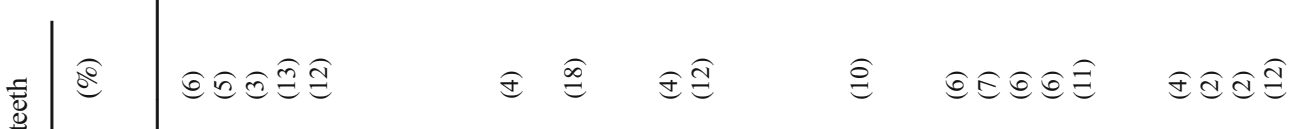

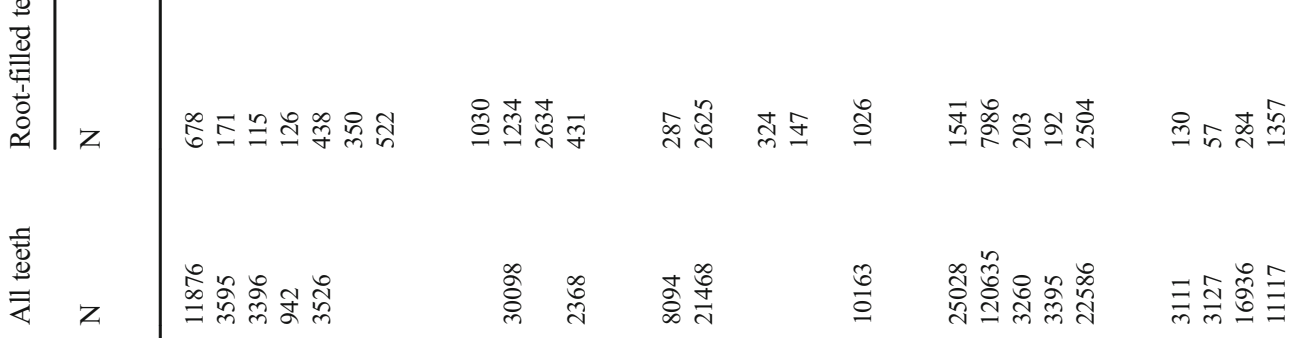

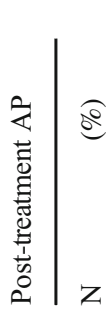

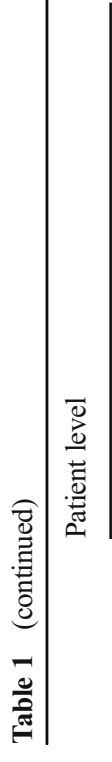

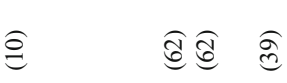

$\widehat{\vartheta}$

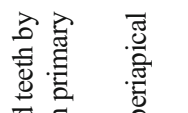

曾.

它

离

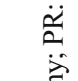

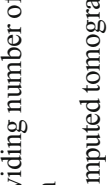

उ.

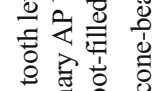

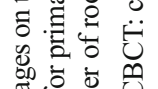

苋造

원

氖言至

过雾安贯

离节

言合焉危

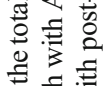

落总言

苛言它

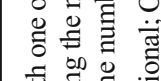

㺼骂

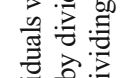

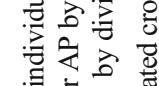

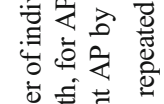

离 苛

氜

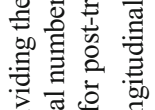

远 형

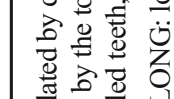

$\infty$ б๙

ब

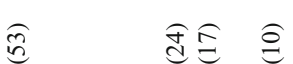

$\widehat{\vartheta}$

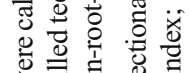

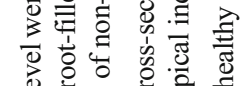

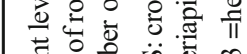

\&

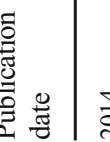

$\stackrel{\circ}{\mathscr{2}}$

F

$\infty$

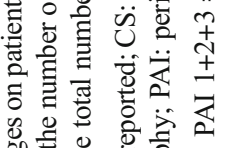

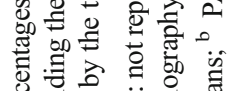

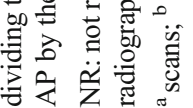


restoration and the prevalence of posttreatment apical periodontitis $[16,17,20,28,30,40]$. Similarly, when the root canal is filled too short of the root apex, the root filling is extruded into the periapex, or the root filling contains voids, the prevalence of posttreatment apical periodontitis increases $[16,17,20-22,24,28,30,37,40,48]$.

\section{Systemic Conditions}

An increasing number of studies are conducted to reveal a possible bidirectional association between the apical periodontitis and the systemic health. This means that a systemic condition can be aggravated by apical periodontitis and, vice versa, that systemically affected individuals are more prone to apical periodontitis. Thus far, limited studies are available on the effect of systemic disease on endodontic outcome [52••, 53-55]. Besides, the evidence is of limited quality and indefinite, which demands that the found associations are to be interpreted with caution [52••]. In order to detect indisputable bidirectional associations between oral disease and the systemic conditions, there is an urgent need for the application of stringent criteria on research reporting [56].

Individuals with uncontrolled diabetes mellitus are reported to have significantly more periapical lesions in comparison to controls with well-controlled diabetes mellitus ( 23 vs. $49 \%$ [23], 9 vs. $18 \%$ [26]). Also, individuals with diabetes mellitus are 1.4 times more likely to have root-filled teeth with apical periodontitis than healthy controls [53]. Apical periodontitis might decrease glycemic control, aggravating diabetes. In turn, diabetes might limit the host's inflammatory response to combat the endodontic infection. In women suffering from postmenopausal osteoporosis, low bone density is reported to be associated with a higher prevalence of apical periodontitis [43]. An association between the prevalence of apical periodontitis and coronary artery disease is reported, where the inflammatory burden of the endodontic infection might be contributing to the systemic condition [29, 32]. Individuals with liver cirrhosis and periapical lesions also had higher Creactive protein levels and a higher prevalence of cirrhosisrelated complications such as ascites, hepatic encephalopathy, and variceal bleeding [44]. Women suffering from inflammatory bowel disease are reported to have more teeth with apical periodontitis and with more severe bone destruction. The prevalence of apical periodontitis was even higher when these women were treated with immunomodulators [47]. Regarding the prevalence of apical periodontitis, there was no significant difference between individuals with rheumatoid arthritis [27] and their healthy counterparts.

\section{Smoking}

Smoking is reported to be one of the strongest predictors of apical periodontitis in a Danish [44] and in a Nigerian population [19]. A Croatian population of smokers had two times more apical periodontitis than the never-smokers did [25]. Smoking might negatively affect the periodontal bone and is associated with dental caries, one of the main causes of apical periodontitis.

Age

Several studies described age as a predictor for apical periodontitis $[19,44]$. The findings of a systematic review and meta-analysis of cross-sectional studies on the prevalence of apical periodontitis and root-filled teeth in persons 65 years of age or older conducted in 2016 do not deviate substantially from the findings of the studies included in this review [57••]. That review confirmed that the prevalence of both apical periodontitis and root-filled teeth increases with age. With aging, not only the comorbidity increases but also the immune system deteriorates. Additionally, oral disease experience in the elderly is higher than younger adults [58]. This might be an important confounder when considering age as a predictor for apical periodontitis.

\section{Conclusions}

Although there seems to be an increase in recent years in studies from less-developed countries and newer detection techniques for periapical disease, such as CBCT, are introduced, the findings from epidemiological studies on the prevalence of primary and posttreatment apical periodontitis in various populations are not substantially different from those from earlier years. It appears that the health of periapical tissues has not majorly improved in the general population, despite technological progress of endodontic treatment and increasing access to healthcare worldwide.

Of all the studied possible predictors, the quality of the coronal restoration and the root filling are the most consistently reported risk factors for apical periodontitis. To identify all possible risk factors efficiently, the design and reporting of epidemiological studies on apical periodontitis should be standardized and improved.

\section{Compliance with Ethical Standards}

Conflict of Interest Rifat Özok and Ilona Persoon declare that they have no conflict of interest.

Human and Animal Rights and Informed Consent This article does not contain any studies with human or animal subjects performed by any of the authors.

Open Access This article is distributed under the terms of the Creative Commons Attribution 4.0 International License (http:// creativecommons.org/licenses/by/4.0/), which permits unrestricted use, distribution, and reproduction in any medium, provided you give 
appropriate credit to the original author(s) and the source, provide a link to the Creative Commons license, and indicate if changes were made.

\section{References}

Papers of particular interest, published recently, have been highlighted as:

- Of importance

•- Of major importance

1. Glickman GN, Schweitzer JL. Endodontic diagnosis. News Lett Am Assoc Endod. 2013:1-6.

2. Kakehashi S, Stanley HR, Fitzgerald RJ. The effects of surgical exposures of dental pulps in germ-free and conventional laboratory rats. Oral Surg Oral Med Oral Pathol. 1965;20:340-9. https://doi. org/10.1016/0030-4220(65)90166-0.

3. Anderson AC, Al-Ahmad A, Elamin F, Jonas D, Mirghani Y, Schilhabel M, et al. Comparison of the bacterial composition and structure in symptomatic and asymptomatic endodontic infections associated with root-filled teeth using pyrosequencing. PLoS One. 2013;8:e84960. https://doi.org/10.1371/journal.pone.0084960.

4. Persoon IF, Buijs MJ, Özok AR, Crielaard W, Krom BP, Zaura E, et al. The mycobiome of root canal infections is correlated to the bacteriome. Clin Oral Investig. 2017;21:1871-81. https://doi.org/ 10.1007/s00784-016-1980-3.

5. Özok AR, Persoon IF, Huse SM, Keijser BJF, Wesselink PR, Crielaard W, et al. Ecology of the microbiome of the infected root canal system: a comparison between apical and coronal root segments. Int Endod J. 2012;45:530-41. https://doi.org/10.1111/j. 1365-2591.2011.02006.x.

6. Hernández Vigueras S, Donoso Zúñiga M, Jané-Salas E, Salazar Navarrete L, Segura-Egea JJ, Velasco-Ortega E, et al. Viruses in pulp and periapical inflammation: a review. Odontology. 2016;104: 184-91. https://doi.org/10.1007/s10266-015-0200-y.

7. Vianna ME, Conrads G, Gomes BP, Horz HP. Identification and quantification of archaea involved in primary endodontic infections. J Clin Microbiol. 2006;44:1274-82. https://doi.org/10.1128/ jcm.44.4.1274-1282.2006.

8. Rohlin M, Kullendorff B, Ahlqwist M, Henrikson CO, Hollender L, Stenström B. Comparison between panoramic and periapical radiography in the diagnosis of periapical bone lesions. Dentomaxillofac Radiol. 1989;18:151-5. https://doi.org/10.1259/ dmfr.18.4.2640445.

9. Dutra KL, Haas L, Porporatti AL, Flores-Mir C, Nascimento Santos J, Mezzomo LA, et al. Diagnostic accuracy of cone-beam computed tomography and conventional radiography on apical periodontitis: a systematic review and meta-analysis. J Endod. 2016;42:356-64. https://doi.org/10.1016/j.joen.2015.12.015.

10. Kanagasingam S, Lim CX, Yong CP, Mannocci F, Patel S. Diagnostic accuracy of periapical radiography and cone beam computed tomography in detecting apical periodontitis using histopathological findings as a reference standard. Int Endod J. 2017;50: 417-26. https://doi.org/10.1111/iej.12650.

11. Estrela C, Bueno MR, Leles CR, Azevedo B, Azevedo JR. Accuracy of cone beam computed tomography and panoramic and periapical radiography for detection of apical periodontitis. $\mathrm{J}$ Endod. 2008;34:273-9. https://doi.org/10.1016/j.joen.2007.11. 023.

12. SEDENTEXCT_Project. Radiation protection $n^{\circ} 172$ : cone beam CT for dental and maxillofacial radiology. Luxembourg: European Commission; 2012. p. 1-156.
13. Orstavik D, Kerekes K, Eriksen HM. The periapical index: a scoring system for radiographic assessment of apical periodontitis. Endod Dent Traumatol. 1986;2:20-34. https://doi.org/10.1111/j. 1600-9657.1986.tb00119.x.

14. Orstavik D. Reliability of the periapical index scoring system. Scand J Dent Res. 1988;96:108-11. https://doi.org/10.1111/j. 1600-0722.1988.tb01415.x.

15. Brynolf I. A histological and roentgenological study of the periapical region of human upper incisors. Odontol Revy. 1967;18:1-175.

16. Alfouzan K, Baskaradoss JK, Geevarghese A, Alzahrani M, Alhezaimi K. Radiographic diagnosis of periapical status and quality of root canal fillings in a Saudi Arabian subpopulation. Oral Health Prev Dent. 2016;14:241-8. https://doi.org/10.3290/j.ohpd. a35299.

17. Cakici EB, Yildirim E, Cakici F, Erdogan AS. Assessment of periapical health, quality of root canal filling, and coronal restoration by using cone-beam computed tomography. Niger J Clin Pract. 2016;19:673-7. https://doi.org/10.4103/1119-3077.188697.

18. Oginni AO, Adeleke AA, Chandler NP. Root canal treatment and prevalence of apical periodontitis in a Nigerian adult subpopulation: a radiographic study. Oral Health Prev Dent. 2015;13:85-90. https://doi.org/10.3290/j.ohpd.a31661.

19. Oginni AO, Adeleke AA, Mejabi MO, Sotunde OA. Risk factors for apical periodontitis sub-urban adult population. Niger Postgrad Med J. 2015;22:105-9.

20. Frisk F, Hugosson A, Kvist T. Is apical periodontitis in root filled teeth associated with the type of restoration? Acta Odontol Scand. 2015;73:169-75. https://doi.org/10.3109/00016357.2014.950182.

21. Ilic J, Vujaskovic M, Tihacek-Sojic L, Milic-Lemic A. Frequency and quality of root canal fillings in an adult Serbian population. Srp Arh Celok Lek. 2014;142:663-8. https://doi.org/10.2298/ SARH1412663I.

22. Hebling E, Coutinho LA, Ferraz CC, Cunha FL, Queluz DP. Periapical status and prevalence of endodontic treatment in institutionalized elderly. Braz Dent J. 2014;25:123-8. https://doi.org/10. 1590/0103-6440201302348.

23. Sanchez-Dominguez B, Lopez-Lopez J, Jane-Salas E, CastellanosCosano L, Velasco-Ortega E, Segura-Egea JJ. Glycated hemoglobin levels and prevalence of apical periodontitis in type 2 diabetic patients. J Endod. 2015;41:601-6. https://doi.org/10.1016/j.joen. 2014.12.024.

24. Kirkevang LL, Vaeth M, Wenzel A. Ten-year follow-up of root filled teeth: a radiographic study of a Danish population. Int Endod J. 2014;47:980-8. https://doi.org/10.1111/iej.12245.

25. Peršić Bukmir R, Jurčević Grgić M, Brumini G, Spalj S, PezeljRibaric S, Brekalo Pršo I. Influence of tobacco smoking on dental periapical condition in a sample of Croatian adults. Wien Klin Wochenschr. 2016;128:260-5. https://doi.org/10.1007/s00508015-0910-8

26. Smadi L. Apical periodontitis and endodontic treatment in patients with type II diabetes mellitus: comparative cross-sectional survey. J Contemp Dent Pract. 2017;18:358-62. https://doi.org/10.5005/jpjournals-10024-2046.

27. Jalali P, Glickman GN, Schneiderman ED, Schweitzer JL. Prevalence of periapical rarefying osteitis in patients with rheumatoid arthritis. J Endod. 2017;43:1093-6. https://doi.org/10.1016/j. joen.2017.02.015.

28. Kielbassa AM, Frank W, Madaus T. Radiologic assessment of quality of root canal fillings and periapical status in an Austrian subpopulation-an observational study. PLoS One. 2017;12: e0176724. https://doi.org/10.1371/journal.pone.0176724.

29. Costa TH, de Figueiredo Neto JA, de Oliveira AE, Lopes E Maia Mde F, de Almeida AL. Association between chronic apical periodontitis and coronary artery disease. J Endod. 2014;40:164-7. https://doi.org/10.1016/j.joen.2013.10.026. 
30. Archana D, Gopikrishna V, Gutmann JL, Savadamoorthi KS, Kumar AR, Narayanan LL. Prevalence of periradicular radiolucencies and its association with the quality of root canal procedures and coronal restorations in an adult urban Indian population. J Conserv Dent. 2015;18:34-8. https://doi.org/10.4103/0972-0707. 148888.

31. Timmerman A, Calache H, Parashos P. A cross sectional and longitudinal study of endodontic and periapical status in an Australian population. Aust Dent J. 2017; https://doi.org/10.1111/adj.12512. This manuscript provides an overview of the epidemiology of root-filled teeth and apical periodontitis during the last decades

32. Liljestrand JM, Mantyla P, Paju S, Buhlin K, Kopra KA, Persson GR, et al. Association of endodontic lesions with coronary artery disease. J Dent Res. 2016;95:1358-65. https://doi.org/10.1177/ 0022034516660509.

33. Bender IB. Factors influencing the radiographic appearance of bony lesions. J Endod. 1997;23:5-14. https://doi.org/10.1016/s00992399(97)80199-9.

34. Dawson V, Petersson K, Wolf E, Akerman S. Periapical status of non-root-filled teeth with resin composite, amalgam, or full crown restorations: a cross-sectional study of a Swedish adult population. J Endod. 2014;40:1303-8. https://doi.org/10.1016/j.joen.2014.05. 002.

35. De Moor RJ, Hommez GM, De Boever JG, Delme KI, Martens GE. Periapical health related to the quality of root canal treatment in a Belgian population. Int Endod J. 2000;33:113-20. https://doi.org/ 10.1046/j.1365-2591.2000.00295.x.

36. Dutta A, Smith-Jack F, Saunders WP. Prevalence of periradicular periodontitis in a Scottish subpopulation found on CBCT images. Int Endod J. 2014;47:854-63. https://doi.org/10.1111/iej.12228.

37. Di Filippo G, Sidhu SK, Chong BS. Apical periodontitis and the technical quality of root canal treatment in an adult sub-population in London. Br Dent J. 2014;216:E22. https://doi.org/10.1038/sj.bdj. 2014.404.

38. Nur BG, Ok E, Altunsoy M, Aglarci OS, Colak M, Gungor E. Evaluation of technical quality and periapical health of root-filled teeth by using cone-beam CT. J Appl Oral Sci. 2014;22:502-8. https://doi.org/10.1590/1678-775720140110.

39. Strindberg IZ. The dependence of the results of pulp therapy on certain factors. Acta Odontol Scand. 1956;14(Suppl 21):1-175.

40. Song M, Park M, Lee CY, Kim E. Periapical status related to the quality of coronal restorations and root fillings in a Korean population. J Endod. 2014;40:182-6. https://doi.org/10.1016/j.joen.2013. 10.017 .

41. Lemagner F, Maret D, Peters OA, Arias A, Coudrais E, GeorgelinGurgel M. Prevalence of apical bone defects and evaluation of associated factors detected with cone-beam computed tomographic images. J Endod. 2015;41:1043-7. https://doi.org/10.1016/j.joen. 2015.03.011. This manuscript presents one of the first epidemiological studies using СBCT and also describes the advantages of CBCT over two-dimensional radiography

42. Halse A, Molven O. A strategy for the diagnosis of periapical pathosis. J Endod. 1986;12:534-8. https://doi.org/10.1016/s00992399(86)80319-3.

43. López-López J, Castellanos-Cosano L, Estrugo-Devesa A, GomezVaquero C, Velasco-Ortega E, Segura-Egea JJ. Radiolucent periapical lesions and bone mineral density in post-menopausal women. Gerodontology. 2015;32:195-201. https://doi.org/10. 1111/ger.12076.

44. Gronkjaer LL, Holmstrup P, Schou S, Schwartz K, Kongstad J, Jepsen $\mathrm{P}$, et al. Presence and consequence of tooth periapical radiolucency in patients with cirrhosis. Hepat Med. 2016;8:97-103. https://doi.org/10.2147/hmer.s113485.
45. Al-Nazhan SA, Alsaeed SA, Al-Attas HA, Dohaithem AJ, AlSerhan MS, Al-Maflehi NS. Prevalence of apical periodontitis and quality of root canal treatment in an adult Saudi population. Saudi Med J. 2017;38:413-21. 10.15537/smj.2017.4.16409.

46. Huumonen S, Suominen AL, Vehkalahti MM. Prevalence of apical periodontitis in root filled teeth: findings from a nationwide survey in Finland. Int Endod J. 2017;50:229-36. https://doi.org/10.1111/ iej.12625.

47. Piras V, Usai P, Mezzena S, Susnik M, Ideo F, Schirru E, et al. Prevalence of apical periodontitis in patients with inflammatory bowel diseases: a retrospective clinical study. J Endod. 2017;43: 389-94. https://doi.org/10.1016/j.joen.2016.11.004.

48. Van der Veken D, Curvers F, Fieuws S, Lambrechts P. Prevalence of apical periodontitis and root filled teeth in a Belgian subpopulation found on CBCT images. Int Endod J. 2017;50:317-29. https://doi. org/10.1111/iej.12631.

49.• Pak JG, Fayazi S, White SN. Prevalence of periapical radiolucency and root canal treatment: a systematic review of cross-sectional studies. J Endod. 2012;38:1170-6. https://doi.org/10.1016/j.joen. 2012.05.023. This manuscript is the first systematic review on endodontic epidemiology

50. Ostrom C, Bair E, Maixner W, Dubner R, Fillingim RB, Ohrbach $R$, et al. Demographic predictors of pain sensitivity: results from the OPPERA study. J Pain. 2017;18:295-307. https://doi.org/10.1016/ j.jpain.2016.10.018.

51. Riley JL 3rd, Gilbert GH, Heft MW. Orofacial pain: patient satisfaction and delay of urgent care. Public Health Rep. 2005;120:140 9. https://doi.org/10.1177/003335490512000207.

52.• Aminoshariae A, Kulild JC, Mickel A, Fouad AF. Association between systemic diseases and endodontic outcome: a systematic review. J Endod. 2017;43:514-9. https://doi.org/10.1016/j.joen.2016. 11.008. This manuscript systematically reviews and assesses the quality of the evidence on bidirectional correlations between systemic conditions and the outcome of endodontic treatment

53. Segura-Egea JJ, Martin-Gonzalez J, Cabanillas-Balsera D, Fouad AF, Velasco-Ortega E, Lopez-Lopez J. Association between diabetes and the prevalence of radiolucent periapical lesions in root-filled teeth: systematic review and meta-analysis. Clin Oral Investig. 2016;20:1133-41. https://doi.org/10.1007/s00784-016-1805-4.

54. Segura-Egea JJ, Castellanos-Cosano L, Machuca G, Lopez-Lopez J, Martin-Gonzalez J, Velasco-Ortega E, et al. Diabetes mellitus, periapical inflammation and endodontic treatment outcome. Med Oral Patol Oral Cir Bucal. 2012;17:e356-61. https://doi.org/10. 4317/medoral.17452.

55. Fouad AF, Burleson J. The effect of diabetes mellitus on endodontic treatment outcome: data from an electronic patient record. J Am Dent Assoc 2003. 2003;134:43-51; quiz 117-118. 10.14219/jada. archive.2003.0016.

56. Bartold PM, Mariotti A. The future of periodontal-systemic associations: raising the standards. Curr Oral Health Rep. 2017; https:// doi.org/10.1007/s40496-017-0150-2.

57.• Hamedy R, Shakiba B, Pak JG, Barbizam JV, Ogawa RS, White SN. Prevalence of root canal treatment and periapical radiolucency in elders: a systematic review. Gerodontology. 2016;33:116-27. https://doi.org/10.1111/ger.12137. This manuscript systematically reviews the literature on periapical disease in a population that is rarely studied, but becoming increasingly relevant

58. Guiglia R, Musciotto A, Compilato D, Procaccini M, Lo Russo L, Ciavarella D, et al. Aging and oral health: effects in hard and soft tissues. Curr Pharm Des. 2010;16:619-30. https://doi.org/10.2174/ 138161210790883813. 